\title{
Fashion Design for Sustainability. A transformative challenge across the European fashion education system
}

\author{
Erminia D'Itria, Federica Vacca
}

Department of Design, Politecnico di Milano, Italy.

\begin{abstract}
Today, we are witnessing the effects that the COVID-19 pandemic has had, and is still having, on social, economic and cultural life worldwide. The educational dimension has seen the regular operating of schools altered: an indeterminate closure of educational institutions, the impossibility to perform face-to-face lectures, and their transposition to digital platforms (Sà et Serpa, 2020). These difficult conditions can be a moment of opportunity to accelerate a process of digital transformation that was beginning to shift in higher education institutions (HEIs). HEIs are using digital transformation strategies to refine how they work, to digitalize their existing operations while designing new digital models, to create entirely new digital models or to fully digitize their current ones (Rodrigues 2017). In the European fashion education system this can result in addressing the transformative challenges that are nurturing the discussion on the future of HEIs (Moja, 2008; Sterling, 2011; Fletcher and Williams, 2013). Therefore, digital innovation becomes the means by which implementing a positive transformation of the sector on key issues that will permeate our daily lives and that can no longer be postponed. Among the pivotal topics there is sustainability which today is slowly trying to establish itself (Wolff, 2020).Trough the analysis of best practices, this paper will decode current behaviors in Fashion Design for Sustainability (FDfS) throughout the European fashion education system.
\end{abstract}

Keywords: Fashion design for sustainability; education; innovation; paradigm transition. 


\section{Addressing the role of Fashion Design HEIs in a sustainable transformation}

The aftermath of the coronavirus pandemic has accelerated an existing process of hybridization typical of the Industry 4.0 paradigm which aims at bridging the physical and digital realms (Agrawal et al., 2021). Increased use of technology to work, socialize and stay connected with the world has given rise to new digital habits. While many European countries are in various stages of recovery, many players, from different sectors, have found themselves prepared for the change of direction thanks to the transformation paths of their activities that have allowed a rapid adaptation to the expectations and digital needs that have emerged in this period. For those who were not prepared, this period is a window of opportunity for accelerating their transformation. In the aftermath of the COVID-19 pandemic, this is especially true regarding the digital and sustainable transitions, which are the two main objectives set by the European Commission to make the continent thrive in the next thirty years (EEA, 2019; European commission, 2019). The post-crisis period will provide unique conditions for shifting supply and production systems to a more desirable state. Government mandates and other responses to the COVID-19 pandemic provide some initial indications of longer-term actions by policymakers, business managers, and others interested in sustainable supply and production, as well as the prospects for sustainability transitions more generally. In the presented context the Fashion sector is among the ones which are struggling to transitioning towards a positive paradigm. As reported by Mckinsy\&Company (2021) some fashion companies won't survive the current crisis while others will emerge better positioned for the future. The criteria by which this will be achieved will mainly depend on their digital and analytics capabilities. These features will not only drive top-line growth but also significantly increase speed, cost, flexibility and according to current times they will guide the sustainability transition across the supply chain (Gonzalo et al., 2021). Within this context, we find the academy that seems obsolete in its effort to strongly include the digital dimension to take advantage of its highly implementable reality. But, as previously argued, the current period could be a period of large-scale re-learning across society capable of triggering sustainable change in many of our current constructs of education and learning (Williams, 2004). There is a growing interest in the university level education institutes and in reshaping their role and nature to address the challenges presented by these transformations. To address the issue related to a sustainable transition a profound change in fashion education is needed enabled and mediated by digital transformation that can reshape the whole fashion system into a more sustainable industry (Bertola and Teunissen, 2018). In support of this transformation, many studies have investigated the impacts of universities on their surrounding contexts, reporting how academies are able to build connections and interact with their external environment these have a positive influence on the growth of all the close systems (Saxenian, 1995). Thus, academic institutions should be vectors of a positive and holistic impact that extend beyond their internal boundaries within disciplines, 
schools, and departments, but also engage outside the fields of business, culture, and civil society by creating awareness and critical consciousness (Weik, 1995; Chesbrough, 2005).

\section{Methodology}

HEIs can play a key role, as major asset to spread awareness about sustainability and embedding a holistic approach for the Fashion sector. There is an increasing need for the academy to be in line with current times, to be able to identifies and codify the patterns of change to transmit knowledge and educate the sector. This could happen through the formation of the new leaders to guide a positive change in this period of transition for the fashion industry towards a more sustainable paradigm. According to this, the paper aims to presents the result of investigation conducted into how HEIs, particularly those working in the FDfS field, are addressing the modern sustainable transition with the help of the digital medium. The data processed are drawn from the knowledge reservoir produced by the Fashion in Process research Lab at Design Department of Politecnico di Milano of which both authors are members. The data were generated from the research conducted by the research Lab (DGGROW, Mapping Fustainable Fashion Opportunities for SMEs, 2019; Erasmus+, FashionSEEDS, 2019) and further implemented with data provided by the $\mathrm{PhD}$ thesis of one of the authors (D'Itria, 2018). Methodologically, three main steps were performed to build an iteratively knowledge: the first step consisted of a desk research on the current practices in the FDfS academic field to map the current sustainability practices among the European HEIs and identified the best practices; the second step consist of an in depth qualitative analysis of the identified best practices; and the last step combined all the data to outline academia directions to implement sustainability through digitalization. The mapping led to the identification of 150 HEIs, located in 23 nations of the European continent, which have distinguished themselves for having reached a mature level within their educational offerings (courses) in relation to the theme of sustainability. The composition of the Institutions was heterogeneous. They were design schools implementing sustainability in their offer, not only in the design field but also in the economics/ management, technology/engineering, and humanities ones. Of the 150 HEIs mapped, 60 were selected as case studies. All these design-based institutions stand out for the way they are pursuing implementations of sustainable theories and practices within their system, often adopting a digital transformation approach as support. The following phase consist of a further analysis through selected face-to-face interviews with representatives from the HEIs which had previously distinguished themselves as best sustainable practices. All the case studies were characterized by a desire to evolve and respond to the new needs of the surrounding environment that is evidenced by the path they are pursuing towards sustainability. The third phase express thrugh the interpretation on the collected data how a transformation in the FDfS education is possible through the implementation of specific didactic aspects: HEIs 
search for rethinking and implementing the traditional educational paths or designing new ones improving through the digital medium the experience of courses, teaching materials, and the training process in general (Abad-Segura et.al., 2020). Today, these qualitative knowledge implementations consider different directions: adopting/implementing a holistic approach, providing an education that facilitates the development of a relationship and transferability between the areas of knowledge and expertise with the world and others; enabling synergies between academia and industry, addressing the fact that successful research development and innovation are networked activities among different actors and sectors; and nurturing a sustainable transformation in FDfS field, imagining the purpose and role of education if humanity successfully transition from an unsustainable way of life to a regenerative one.

\subsection{Holistic thinking}

Modern HEIs deliver knowledge within the framework of their curriculum, but also train students with skills that will enable them to address real-world issues (Altinyelken, 2015). To meet these expectations about sustainability is necessary for HEIs to adopt a holistic approach to the knowledge: systematizing and combining the four founding pillars to offer elementary knowledge through a series of overarching topics which can guide students in facing the complexity of future issues they will meet on their path. This need for holism in the education field has been the focus of debate informed by several scholars who have theorized this approach in accordance with the themes of education for sustainability (Wiek, at al., 2011; Giangrande et al., 2019), as well as the theories about the Education for Sustainable development (Sterling, 2010; Huckle, 2010). Today, as HEIs have been permeated by the technological advancement that the current historical moment brings with it, the holistic passage must deal with a digital transformation in all dimensions. The presented holistic approach has been impacted by digital transformation and has responded to this phenomenon integrating the digital dimension to filter the complex relationships between actors in a technologically supported education domain. But this transformation is translated in more than just technology. The goal is to adopt new ways of working to continue delivering knowledge and services in the face of changing technology and the resuting competitions, audience needs, and behaviors. It is especially conceived to face the transition from the traditional vision of HEIs towards a multifaced ecosystem which asserts that everything exists in relationship, in a context of connections and meanings (Miller, 2005) which are facilitated by the digital medium that becomes the vector of this holistic approach.

\subsection{Sustainable transformation in FDfS education}

Over the past decades, international organizations have agreed on the role of education as a fundamental element of sustainable development. Today, this role is more relevant than ever as recognized by UNESCO in the formulation of its post-covid strategies (UNESCO,2020). 
In this context, FDfS aims at incorporating the core issues of sustainable development into fashion design education and learning and supporting the passage to a new positive model. To reach this objective, HEIS operating in the FDfS field need to adopt approaches which can enable to successfully handle the issues which current times are prospecting to imagine feasible, plausible, and desirable visions of the future (Strunk, 2014). This is particularly true for the context in which they refer, fashion, as this is the second most impactful industry in the world after oil, both in terms of environmental and human capital (UN,2019). Therefore, a deep systemic change towards sustainability is needed: a transformative sustainable educational model. This new model needs to give a strategic guidance to facilitate the transition from the dominant mechanistic of transmissive educational model to the transformative one (Sterling, 2011). Today, FDfS HEIs translate this into further improvement of internal sustainability and transformation practices to address emerging fashion industry transformations on which to act simultaneously to solve problems and shift systems: the diffusion of sustainability issues, and the wide effects and improvements of digital transformation. This transformation becomes the means to accelerate the transition to more positive paradigms. This does not simply refer to the shift of lessons from the offline to the online paradigm, but in a deeper way it concerns the need to revise the approach between physical and digital reality. Indeed, technology becomes a vector of systemic change and accelerates and implements it by overcoming the physical barrier. Therefore, FDfS universities are developing specific digital strategies in reaction to the massive shift towards the use of new technologies but also in an attempt to break down their own internal barriers that tend to limit vision and block the development of practicess that can effectively implement a digital transformation (PSRC, 2018). A digital transformation in the field of FDfS is not only about technological advancement, but goes beyond that and generates profound changes that can affect pedagogical approaches, teaching practices and its activities, research, as well as the people immersed in it.

\subsection{Academy-Industry collaboration/relationship}

Today HEIs are involved in a transition towards a new sustainable paradigm which is transforming the current FDfS education system. The old compartmentalized one is giving way to new models that strategically view the system in which they operate as the union of different parts: no more separation among the different institutional spheres which operates - HEIs, and industry - but an open system to make innovations concerning knowledge, technologies, and systems thrive (Gomez-Gaquet et al., 2016). Therefore, is necessary to encourage an interdisciplinary approach as today we assist to a passage from knowledge transfer to knowledge exchange between HEIs and industry to reach common objectives (Eriksson, 2016), as the passage to a sustainable paradigm. The necessity of these collaborations between university and industry rises the needs for coordinating various disciplines within an organization, sharing information, experiences and creating an 
understanding of the common systems. If all the actors involved in these mutual exchanges set their objectives and share their aims this can be translated in the creation of a stable environment to foster an ecosystem for a positive and sustainable innovation lead by digitalization. In this context, institutional perspective is a fertile lens for reading digital transformation as the effect of several technological innovations that result in new actors, and networks, models, behaviors, and values (Hinings, 2018). Heis, with the support of industry and professionals, through the spread of external advisory board or steering committee, become the channel for identifying, codifying, and modeling these new actors and how they relate to each other and their surroundings. Through a flow of mutual exchange, between HEIs and industry, multidisciplinary knowledge and skills are explored for application in increasingly changing educational, professional, and labor market contexts.

\section{Conclusions}

The study analyzed the main directions in FDfS education. A mixed methodology allowed to identify current directions in FDfS within European HEIs which are embedding sustainability in their systems. The main categories identified highlighted how they are often aided by the digital medium. This indicates that the relationship between sustainability and digital innovation in HEIs has connotations related to holistic practices, embedding technologies, interdisciplinary practices, and nurturing a transformative education model. This study has some limitations, it has been based on a mature sector, as is the fashion education system in Europe. The results should be understood in this framework. Future lines in this area of research must contemplate, among others, the possibility for lead actors in the HEIs system to explore new directions in order to meet the different needs of students and educators, as well asecternal partners as the industry, who aim to engage with sustainability topics and practices. They can be used as guidelines to address all the possible issues related to validating, planning, or re-shaping educational experiences in the fashion field. Finally, it is necessary to highlight how the Fashion educational practices presents a resource for the development of a sustainable curriculum, on a large scale. This could means a positive change for the European HEIs system from impacting to the sustainable paradigm.

\section{Acknowledgements}

This paper is the result of common research and findings; nevertheless, Federica Vacca edited section 1, and Erminia D'Itria sections 2 and 3. The methodology presented is the result of research studies and projects undertaken in recent years by Fashion in Process (Fip), a multidisciplinary research laoratory within the Design Department of Politecnico di Milano. 


\section{References}

Abad-Segura, E., González-Zamar, M.-D., Infante-Moro, J. C., \& Ruipérez García, G. (2020). Sustainable Management of Digital Transformation in Higher Education: Global Research Trends. Sustainability, 12(5), 2107. doi:10.3390/su12052107

Altinyelken, H. K. (2015). Evolution of curriculum systems to improve learning outcomes and reduce disparities in school achievement. (EFA GMR background report; No. ED/EFA/MRT/2015/PI/13). http://unesdoc.unesco.org/images/0023/002324/232420e.pdf

UNESCO.

Agrawal, M., Dutta, S., Kelly, R., \& Millán, I. (2021, January 20). COVID-19: An inflection point for Industry 4.0. McKinsey \& Company.

Bertola, P. and Teunissen, J. (2018), "Fashion 4.0. Innovating fashion industry through digital transformation", Research Journal of Textile and Apparel, Vol. 22 No. 4, pp. 352-369. https://doi.org/10.1108/RJTA-03-2018-0023

Chesbrough, H. W. (2003). Open innovation: The new imperative for creating and profiting from technology. Boston, Mass: Harvard Business School Press.

D'Itria, E. (I/P). Driving sustainable change in fashion through design. (PhD thesys).

Eriksson, Y. (2016). Interdisciplinary learnin: meeting future challenges. In Vacca, F., Warshavski, T. (Ed.), Interdisciplinary research and education agenda. A design driven perspective (pp. 35-41). Mandragora.

European Commission . European Commission; Brussels: 2019. The European Green Deal.

European Environment Agency (EEA) EEA; Copenhagen: 2019. Sustainability Transitions: Policy and Practice, EEA Report No 9/2019

Fletcher, K. and Williams, D. (2013), "Fashion Education in Sustainability in Practice", Research Journal of Textile and Apparel, Vol. 17 No. 2, pp. 81-88.

Giangrande , N, White, R M , East , M , Jackson, R, Clarke, T, Saloff Coste , M \& PenhaLopes, G 2019 , ' A competency framework to assess and activate education for sustainable development : addressing the UN Sustainable Development Goals 4.7 Challenge ' , Sustainability , vol. 11 , no. 10, 2832 . https://doi.org/10.3390/su11102832

Gòmez-Gasquet, P., Cuenca, L., Boza, A., Alfaro-Saiz, J., Verdecho, M., Vincens-Salort, E., Poler, R. (2016). Industry-academy collaboration: an open innovation framework. In Vacca, F., Warshavski, T. (Ed.), Interdisciplinary research and education agenda. A design driven perspective (pp. 35-41). Mandragora.

Gonzalo, A., Harreis, H., Altable, C. S., \& Villepelet, C. (2021, February 12). Fashion's digital transformation: Now or never. McKinsey \& Company.

Hinings, B., Gegenhuber, T., \& Greenwood, R. (2018). Digital innovation and transformation: An institutional perspective. Information and Organization, 28(1), 52/61

Huckle, J. (2010). ESD and the Current Crisis of Capitalism: Teaching Beyond Green New Deals. Journal of Education for Sustainable Development, 4(1), 135-142.

Kumar, T.M.V.; Dahiya, B. (2017). Smart Economy in Smart Cities. In Smart Economy in Smart Cities: International Collaborative Research (pp. 3-76). Kumar, T.M.V. (Ed.). Springer. 
Miller, John P. (2005): Conclusion: Seeking Wholeness. In: John P. Miller (Hg.): Holistic learning and spirituality in education. Breaking new ground. Albany: State University of New York Press, pages. 233-236

Moja, T. (2008). Institutional challenges and implications for HEIS: transformation, mission and vision for the 21st century. Article. Retrieved from http://hdl.handle.net/2099/8114

Rodrigues, L.S. Challenges of digital transformation in higher education institutions: A brief discussion. In Proceedings of the 30th International Business Information Management Association Conference, IBIMA 2017/Vision 2020, Madrid, Spain, 8-9 November 2017.

Public Sector Research Centre, 2018. The 2018 Digital University: Staying Relevant in the Digital Age. Retrieved from : https://www.pwc.co.uk/assets/pdf/the-2018-digitaluniversity-staying-relevant-in-the-digital-age.pdf (accessed on February 2021).

Sá, M. J., \& Serpa, S. (n.d.). The COVID-19 Pandemic as an Opportunity to Foster the Sustainable Development of Teaching in Higher Education.

Saxenian, A. L. (1996). Regional advantage: Culture and competition in Silicon Valley and Route 128. Cambridge, Mass: Harvard University Press.

Sterling, S. (2011). Transformative learning and sustainability: Sketching the conceptual ground. Learning and Teaching in Higher Education, 5, 17-33.

Sterling, S. (2001). Sustainable education: Re-visioning learning and change. UK: Green Books.

Strunk, Frederike. (2014). The German Enquete Commission on growth, prosperity and quality of life: a model for futures studies? European Journal of Futures Research, (2), 58-65.

UNESCO. (2020). Education in a post-COVID world: Nine ideas for public action International Commission on the Futures of Education.

UN launches drive to highlight environmental cost of staying. UN News. https://news.un.org/en/story/2019/03/1035161. (2019, March 28).

Weick, K. E. (1995). Sensemaking in organizations. Thousand Oaks: Sage Publications.

Williams, R. (2004) See Change: Learning and education for sustainability, New Zealand Parliamentary Commission for the Environment.

Wolff, L.-A. (2020). Sustainability Education in Risks and Crises: Lessons from Covid-19. Sustainability, 12(12), 5205. https://doi.org/10.3390/su12125205 